\title{
EFEKTIVITAS PEMBERIAN TERAPI AKUPUNKTUR DENGAN KOMBINASI TITIK AKUPUNKTUR BI-23 (SHENSHU), BI-40 (WEIZHONG) DAN BI-23 (SHENSHU), KI 3 (TAIXI) TERHADAP PERBAIKAN KELUHAN NYERI PADA KASUS NYERI PUNGGUNG BAWAH DI POSYANDU LANSIA KLODRAN DAN BENDO COLOMADU KARANGANYAR
}

\author{
Heni Nur Kusumawati, Estuningsih, Risna Widowati \\ Kementerian Kesehatan Politeknik Kesehatan Surakarta Jurusan Akupunktur
}

\begin{abstract}
Lower Back Pain (NPB) or Low Back Pain (LBP), VAS, Acupuncture Therapy, Healing Effect. Previous studies of acupuncture for low back pain were conducted. In this study researcher used combination of BL 23. BL 40 and BL 23, KI 3. This study is aimed to determine the effectiveness of combination of BL 23. BL 40 and BL 23, KI 3 for recovery low back pain. This study is done during March until May 2015 at Posyandu Lansia Klodran and Bendo Colomadu Karanganyar. This is quasy experiment research with pre test and post test. Thirty subject study were divided into two groups were treated combination of BL 23. BL 40 in first group and BL 23, KI 3 in second group. This treatment was conducted for 10 times. VAS was done before and after $10^{\text {th }}$ therapy. The data obtained thus was analyzed using the Mann-Whitney test. Twenty nine out of thirty subjects experienced decrease their VAS only one subject did not show any alteration. The average value of VAS decrease is 3.03. Acupuncture therapy with combination of of BL 23. BL 40 and BL 23, KI 3 has been shown that there are no different between two groups ( $p>0.05)$
\end{abstract}

Keywords : Lower Back Pain (NPB) or Low Back Pain (LBP), VAS, Acupuncture Therapy, Healing Effect

Abstrak: Nyeri Punggung Bawah (NPB) atau Low Back Pain (LBP), VAS, Terapi
Akupunktur, Efek Kesembuhan. Penelitian terkait dengan akupunktur untuk nyeri
punggung bawah telah banyak dilakukan. Dalam penelitian ini menggunakan kombinasi
titik BL 23, BL 40 dan kombinasi titik BL 23, KI 3. Penelitian ini ditujukan untuk
mengetahui efektivitas terapi akupunktur dengan kombinasi titik BL-23 Shenshu, BL-40
Weizhong dan BL-23 Shenshu KI-3 Taixi terhadap perbaikan keluhan nyeri pada kasus
Low Back Pain. Penelitian dilakukan selama Maret - Mei 2015 dan di Posyandu Lansia
Klodran Dan Bendo Colomadu Karanganyar. Penelitian dilakukan dengan melakukan
penusukan pada kombinasi titik BL 23, BL 40 pada kelompok petama dan kombinasi
titik BL 23, KI 3 pada kelompok kedua. Terapi dilakukan selama 10 kali terapi.
Penghitungan VAS dilakukan sebelum dan sesudah terapi ke-10. Jenis penelitian ini
adalah quasi experiment dengan pre test dan post test dan metode analisis data yang
digunakan adalah dengan uji Mann-Whitney. Dari 30 subyek penelitian, sebanyak 29
subyek dari total dua kelompok mengalami penurunan nilai VAS dan hanya satu subyek
penelitian saja yang tidak mengalami penurunan nilai VAS. Nilai rata-rata penurunan
VAS sebesar 3,03. Terapi akupunktur menggunakan kombinasi titik BL 23, BL 40 dan 
kombinasi titik BL 23, KI 3 pada kedua kelompok menunjukkan tidak ada perbedaan dalam menurunkan nilai VAS dengan nilai p>0,05 pada uji Mann-Whitney.

Kata Kunci : Nyeri Punggung Bawah (NPB) atau Low Back Pain (LBP), VAS, Terapi Akupunktur, Efek Kesembuhan.

\section{PENDAHULUAN}

Nyeri punggung bawah (NPB) atau Low Back Pain (LBP) adalah nyeri di daerah punggung antara sudut bawah kosta (tulang rusuk) sampai lumbosakral (sekitar tulang ekor). Nyeri juga bisa menjalar ke daerah lain seperti punggung bagian atas dan pangkal paha. Low Back Pain atau nyeri punggung bawah merupakan salah satu gangguan muskuloskeletal yang disebabkan oleh aktivitas tubuh yang kurang baik (Hutchinson, Ball, Andrews and Jones, 2012). Faktor resiko nyeri pinggang meliputi usia, jenis kelamin, berat badan, etnis, merokok, pekerjaan, paparan getaran, angkat beban yang berat yang berulang-ulang, membungkuk, duduk lama, geometri kanal lumbal spinal dan faktor psikososial (Bimariotejo, 2009). Sifat dan karakteristik nyeri yang dirasakan pada penderita LBP bermacammacam seperti nyeri terbakar, nyeri tertusuk, nyeri tajam, hingga terjadi kelemahan pada tungkai (Idyan, 2008). Nyeri ini terdapat pada daerah lumbal bawah, disertai penjalaran ke daerahdaerah lain, antara lain sakroiliaka, koksigeus, bokong, kebawah lateral atau posterior paha, tungkai, dan kaki (Bimariotejo, 2009). Seorang ahli akupunktur Jerman dari Universitas Regensburg, Dr. Michael Haq mengatakan bahwa akupunktur adalah terapi yang lebih efektif untuk pengobatan nyeri pinggang. Pada penelitian yang pernah dilakukan, terapi akupunktur memberikan efek kesembuhan untuk nyeri pinggang sebesar $74 \%$ dan memiliki efek samping minimal dibandingkan dengan terapi pengobatan yang lain (Baldry, 2005).

Nyeri punggung bawah (NPB) sering menjadi penyebab anggota masyarakat merasakan penurunan kemampuan pada aktifitas fungsional sehari-hari. Penderita NPB menyampaikan keluhan nyeri, spasme otot dan gangguan fungsi. Adanya kaku otot akan menimbulkan keluhan nyeri yang berkepanjangan yang pada akhirnya akan memperburuk keadaan sehingga penderita akan mengeluh adanya penurunan fungsi pada aktivitas tertentu anatara lain mereka tidak mampu berjalan dengan tegak serta diikuti fleksibilitas punggung yang kurang (tidak maksimal) dan lain sebagainya. Demikian yang disampaikan oleh beberapa lansia yang berkunjung di Posyandu Lansia di Klodran dan Bendo Colomadu. Bahwa rata-rata pengunjung Posyandu Lansia di Klodran dan Bendo Colomadu dari total pengunjung sejumlah 89 orang dengan keluhan nyeri punggung bawah 83 orang $(93,2 \%)$.

Berdasarkan fenomena dan permasalahan yang berkembang di masyarakat sebagaimana dipaparkan di atas maka proposal ini mengangkat judul "Efektifitas Pemberian Terapi Akupunktur Dengan Kombinasi Titik Akupunktur BL-23 Shenshu, BL-40 Weizhong Dan BL-23 Shenshu KI-3 (Taixi) Terhadap Perbaikan Keluhan Nyeri pada Kasus Low Back Pain Di Posyandu Lansia Klodran dan Bendo Colomadu. 


\section{METODE PENELITIAN}

Penelitian ini merupakan quasi experiment dengan pre test dan post test yaitu rancangan penelitian yang hanya menggunakan dua kelompok subyek penelitian, pengukuran dilakukan sebelum dan setelah perlakuan (Saryono, 2008).

Pretes Terapi akupunktur pada BL 23 dan BL 40 Posttest

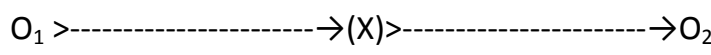

Keterangan :

O1 : kelompok pertama sebelum diberikan terapi akupunktur (pretest)

$\mathrm{X} \quad$ : perlakuan yaitu pemberian terapi akupunktur pada titik BL 23

(Shenshu) dan BL 40 (Weizhong) (eksperimen)

$\mathrm{O} 2$

: kelompok pertama setelah diberikan terapi akupunktur (posttest).

\section{HASIL PENELITIAN}

Penelitian dengan judul efektivitas terapi akupunktur dengan kombinasi titik BL-23 Shenshu, BL-40 Weizhong dan BL-23 Shenshu KI-3 Taixi terhadap perbaikan keluhan nyeri pada kasus nyeri punggung bawah di Posyandu Lansia Klodran dan Bendo Colomadu Karanganyar yang penulis lakukan selama 2 bulan. Adapun tahapan penelitian yang penulis lakukan adalah melakukan survei pendahuluan di Desa Klodran dan Bendo untuk mengetahui jumlah lansia yang mengalami nyeri punggung bawah. Setelah proposal penelitian diajukan, peneliti kemudian melakukan teknik pengambilan sampel dengan total sampling sejumlah 30 subyek penelitian. Sebelum dilakukan intervensi terhadap subyek penelitian, peneliti melakukan pengambilan data VAS (Visual Analog Scale) masing-masing subyek penelitian.
Pengambilan data subyek dilakukan di Posyandu Lansia Klodran dan Bendo Colomadu, Karanganyar.

Adapun sebelum intervensi dilakukan, peneliti membagi subyek penelitian dalam dua kelompok yang masing-masing terdiri dari 15 subyek penelitian. Terapi akupunktur dilakukan sesuai dengan jadwal kelompok masingmasing. Jadwal terapi untuk kelompok pertama adalah hari Senin dan Rabu sedangkan jadwal terapi untuk kelompok kedua dilakukan pada hari Selasa dan Kamis. Intervensi dilakukan selama 10 kali terapi. Peneliti mengambil VAS (Visual Analog Scale) setelah terapi akupunktur ke-10 selesai dilakukan.

\section{PEMBAHASAN}

Hasil analisis univariat didapatkan bahwa dari 30 subyek penelitian, sebanyak 2 subyek mengalami kenaikan nilai VAS dan 1 orang subyek tidak mengalami perubahan sama sekali, sisanya sebanyak 29 subyek mengalami penurunan VAS. Hal ini bisa disebabkan karena subyek penelitian yang kurang melakukan aktivitas fisik. Kurangnya aktivitas fisik dapat mempengaruhi sistem muskuloskeletal seseorang sehingga seorang individu yang kurang aktivitas fisik dapat menghambat aliran Qi dan darah yang mengakibatkan punggung bawah menetap (Felicity,2011).

Nilai rata-rata penurunan VAS pada penelitian ini sebesar 3. Nilai ini cukup memberikan hasil yang memuaskan untuk nyeri punggung bawah. Penelitian yang dilakukan oleh Engstrom (2008) dalam (Wilke, et al., 2014) menunjukkan hasil yang signifikan terhadap penurunan nyeri punggung bawah. Terapi dilakukan $3 x /$ minggu selama 3 bulan. terjadi penurunan yang signifikan jika 
dibandingkan dengan akupunktur tubuh. Hal ini juga didukung oleh penelitian yang dilakukan oleh Jing et al (2008) dalam (Macpherson, et al.,2013) terapi akupunktur yang dilakukan secara rutin dapat memberikan hasil yang baik dalam menurunkan nyeri punggung bawah.

Hal ini dapat disimpulkan bahwa terapi akupunktur efektif jika dilakukan secara rutin. Selain itu, waktu yang digunakan untuk terapi juga harus lebih lama yaitu minimal 2 seri terapi atau sekitar 8 minggu agar hasil penurunan VAS lebih signifikan. Sedangkan pada penelitian ini murni hanya dengan terapi akupunktur pada dua titik saja dengan waktu yang relatif singkat yaitu 1 seri terapi atau 4 minggu penelitian, sehingga hasil penurunan VAS juga tidak terlalu besar. Hal ini sesuai dengan hasil penelitian diatas yang menyatakan bahwa hanya satu subyek penelitian saja yang sembuh dan tidak merasakan nyeri punggung bawah sama sekali dengan skala VAS 0.

Terapi akupunktur merupakan metode terapi yang memandang dan mengatasi penyakit secara holistik (Saputra, 2005) sehingga terapi akupunktur khususnya antara kelompok pertama (kombinasi BL 23, BL 40) dengan kelompok kedua (BL 23, KI 3) dapat dikombinasikan dengan pengaturan pola hidup yang sehat terutama latihan fisik ringan pada lansia agar memberikan hasil yang lebih baik dalam penurunan VAS.

\section{KESIMPULAN DAN SARAN}

Usia subyek penelitian yang mengalami nyeri punggung bawah terbanyak adalah diantara usia 66 tahun sampai dengan 90 tahun dengan rata-rata usia 66 tahun.
VAS sebelum dan sesudah terapi Akupunktur didapatkan bahwa nilai signifikansi $\mathrm{p}=0,085>0,05$ maka Ho diterima yang artinya tidak ada perbedaan nilai VAS sebelum dan sesudah terapi Akupunktur antara kelompok pertama (kombinasi BL 23, BL 40) dengan kelompok kedua (BL 23, KI 3).Terapi akupunktur dengan kombinasi titik BL 23, BL 40 dan kombinasi titik BL 23, KI 3.

Terapi akupunktur antara kelompok pertama (kombinasi BL 23, BL 40) dengan kelompok kedua (BL 23, KI 3) sama-sama efektif menurunkan skala nyeri VAS tetapi diantara keduanya tidak ada perbedaan yang signifikan.

Saran pada penelitian ini adalah; Titik yang digunakan untuk penelitian selanjutnya diharapkan berbeda sehingga tidak ada titik yang sama antar kelompok yang berbeda, Adanya kelompok kontrol pada penelitian selanjutnya diharapkan dapat memberikan kontrol terhadap hasil penelitian bahwa hasil penurunan skala nyeri VAS benar-benar karena terapi akupunktur yang telah dilakukan bukan karena faktor yang lain, Desain penelitian yang digunakan diharapkan lebih baik lagi yaitu untuk menghindari bias dengan menggunakan RCT (Randomized Controlled Trial), Besarnya sampel penelitian lebih diperbesar lagi agar hasil yang didapatkan lebih signifikan.

\section{DAFTAR RUJUKAN}

Engstrom, JW. Back and Neck Pain. Anthony S Fauci, Dennis L Kasper, dkk. (2008). Harrison's Principle of Internal Medicine. Edisi 17 Volume 1. United States of America : The Mc-Graw-Hill Companies. 107-114. 
Felicity L. Bishop, Shipu Zaman, George T. Lewith. (2011). Acupuncture for low back pain: A survey of clinical practice in the UK. Complementary Therapies in Medicine: 19, 144148.doi:10.1016/j.ctim.2011.03.004.

Hutchinson AJ, Ball S, Andrews JC, Jones GG. (2012). The effectiveness of acupuncture in treating chronic nonspecific low back pain: a systematic review of the litera-ture. J Orthop Surg Res: 7:36

J. Wilke, L. Vogt, D. Niederer, M. Hubscher, J. Rothmayr, D. Ivkovic, M. Rickert, W. Banzer. (2014). Short-term effects of acupuncture andstretching on myofascial trigger point painof the neck: A blinded, placebo-controlledRCT.

Complementary Therapies in Medicine: 22, 835-841. doi.org/10.1016/j.ctim.2014.09.001.
Jing Yuan, Nithima Purepong, Daniel Paul Kerr,Jongbae Park, Ian Bradbury, and Suzanne McDonough. (2008). Effectiveness of Acupuncture for Low Back Pain. Spine Journal. Volume 33, Number 23, pp E887-E900.

MacPherson H, Maschino AC, Lewith G, Foster NE, Witt C, et al. (2013). Characteristics of Acupuncture Treatment Associated with Outcome: An Individual Patient Meta-Analysis of 17,922 Patients with Chronic Pain in Randomised Controlled Trials. PLoS ONE 8(10): e77438.doi:10.1371/journal.pone.00 77438 . 